\title{
Erratum to: Decomposition of multi-class pharmaceutical residues in wastewater by exposure to ionising radiation
}

\author{
I. Reinholds ${ }^{1,2} \cdot$ I. Pugajeva ${ }^{1,2}$ - I. Perkons ${ }^{1,2}$ - E. Lundanes ${ }^{3}$ - J. Rusko ${ }^{1,2}$.

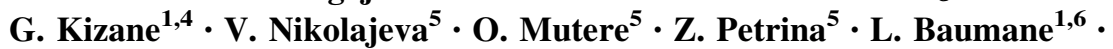 \\ V. Bartkevics ${ }^{1,2}$
}

Published online: 4 April 2017

(C) Islamic Azad University (IAU) 2017

Erratum to: Int. J. Environ. Sci Technol.

DOI 10.1007/s13762-017-1290-6

The affiliations in the original article contain errors. The correct affiliations are given below.

The online version of the original article can be found under doi:10. 1007/s13762-017-1290-6.

\footnotetext{
I. Reinholds

ingars.reinholds@lu.lv

1 Faculty of Chemistry, University of Latvia, Jelgavas iela 1, Riga 1040, Latvia

2 Institute of Food Safety, Animal Health and Environment "BIOR", Lejupes iela 3, Riga 1076, Latvia

3 Department of Chemistry, University of Oslo, Blindern, Post Box 1033, 0315 Oslo, Norway

4 Institute of Chemical Physics, University of Latvia, Jelgavas iela 1, Riga 1040, Latvia

5 Department of Microbiology and Biotechnology, University of Latvia, Jelgavas iela 1, Riga 1040, Latvia

6 Latvian Institute of Organic Synthesis, Aizkraukles iela 21, Riga 1006, Latvia
} 